\title{
Homeownership, mortgages, and unemployment
}

\author{
Yuval Kantor • Jan Möhlmann • \\ Peter Nijkamp • Jan Rouwendal
}

Received: 18 April 2014 / Accepted: 9 February 2015 / Published online: 24 February 2015

C) The Author(s) 2015. This article is published with open access at Springerlink.com

\begin{abstract}
According to Oswald's thesis, homeownership increases unemployment. Empirical research on micro-data has indeed confirmed that unemployed homeowners are less inclined to change their residential location and accept a new job elsewhere. However, it is also repeatedly found that unemployed homeowners tend to find a job more easily than otherwise comparable tenants. This paper aims to make a new contribution to the scientific debate on Oswald's thesis by addressing the risk attitudes of job seekers. We show that decreasing absolute risk aversion implies that the exit rate from unemployment is increasing in housing costs, in the context of a standard job search model. Therefore, the higher costs associated with leveraged homeownership may be the driving force of homeowners' observed labor market performance. We test this prediction on the basis of Dutch data on individual unemployment spells. Contrary to our hypothesis, we do not find evidence that a higher mortgage is associated with higher exit rates from unemployment. Rather, our findings support earlier microeconometric results that homeownership tends to accelerate a successful job search.
\end{abstract}

Keywords Homeownership - Unemployment duration · Mortgage

JEL Classification J6 $\cdot$ R2

\section{Introduction}

The relationship between homeownership and unemployment is an intriguing one. According to Oswald's thesis (see Oswald 1996, 1997, 1999) there is a positive cor-

Y. Kantor · J. Möhlmann · P. Nijkamp · J. Rouwendal ( $\varangle)$

Department of Spatial Economics, VU University, De Boelelaan 1105,

1081 HV Amsterdam, The Netherlands

e-mail: j.rouwendal@vu.nl 
relation between the two: a ten percentage points increase in the share of homeowners is associated with a two percentage points increase in unemployment. Recently, Blanchflower and Oswald (2013) have reconsidered the thesis. They argue that

"rises in the homeownership rate in a U.S. state are a precursor to eventual sharp rises in unemployment in that state. The elasticity exceeds unity: a doubling of the rate of home-ownership in a U.S. state is followed in the long-run by more than a doubling of the later unemployment rate." (Blanchflower and Oswald 2013, abstract)

In the remainder of their paper the authors discuss a number of possible causal mechanisms behind the correlation they observe, that need further investigation. The connection between homeownership and unemployment is policy-relevant, as in many countries homeownership is encouraged (for instance, by the tax deductibility of mortgage interest payments). Thus Oswald's thesis prompts questions of both a policy and a research nature, as is also witnessed in studies by Coulson and Fisher (2009) and Green and Hendershott (2001).

In this paper we examine some of the possible causal mechanisms behind the apparently substantial impact of homeownership on labor market outcomes. The next section discusses some issues associated with the interpretation of existing empirical evidence. In Sect. 3 we present a model in which housing tenure and mortgage payments interact with unemployment. In our model the higher exit rates from unemployment of searchers with high housing costs are related to decreasing absolute risk aversion, which is widely believed to be a realistic property of human behavior under risk. The results of an empirical estimation of the model on the basis of Dutch data are reported in Sect. 4, while Sect. 5 concludes.

\section{Unemployment and residential mobility}

An apparently plausible mechanism that potentially explains Oswald's thesis is that homeownership decreases the possibility of workers to react to shocks through its impact on the costs of residential mobility. Homeowners are likely to be more reluctant to move to other regions in response to changing labor markets, because of higher moving costs. For example, in the Netherlands buyers of real estate have to pay a transaction tax, which is currently $2 \%$. Since a large share of the rental market in the Netherlands is subsidized social housing, this may lead to substantial transaction costs of moving for renters as well. Examples of such transaction costs are waiting times or the loss of subsidy by moving out of social housing to the private rental market. A number of microeconometric studies have confirmed that residential mobility related to job search of unemployed workers is lower among homeowners. However, these studies also found exactly the opposite of Oswald's thesis: homeowners tend to find a job faster than otherwise comparable tenants after they become unemployed (Munch et al. 2006, for Denmark; Battu et al. 2008, for the UK; Van Vuuren 2007, for the Netherlands). The explanation of this finding is that homeowners more often accept a job on the local labor market than tenants do, whereas the reverse is true on the national labor market. The latter effect is in accordance with Oswald's thesis. However, the former effect dominates, as a common finding of the empirical work is that residential 
mobility related to job mobility is very limited. For instance, Munch et al. (2006) report that only $1.2 \%$ of the unemployment spells in their Danish data end with employment in a distant labor market. The low rates of residential mobility challenge any attempt to explain the correlation between homeownership and unemployment on the basis of differences between tenants and owners in their propensity to accept a non-local job. At least in European countries, residential mobility associated with finding a new job is simply too uncommon to make a large difference in regional or national unemployment rates (see also Van den Berg and Gorter 1997; Van Ommeren et al. 2000).

Another implication of higher transaction costs of moving is that it reduces the ability to absorb negative income shocks by reducing housing costs. If transaction costs would restrict the ability to reduce housing costs, a decrease in income would be fully translated into non-housing consumption. In this case the income reduction would cause a higher fall in utility. Chetty and Szeidl (2007) discuss how consumption commitments such as owning a house can impact risk aversion. The impact of this on search behavior can be an alternative explanation for the higher exit rate of homeowners. However, since empirical studies show that residential mobility during unemployment is very low, our model does not take into account differences in transaction costs of moving between homeowners and renters.

The empirical result that homeowners have higher exit rates from unemployment cannot be explained by standard job search models. These models predict that a tighter constraint on residential mobility, such as higher moving costs, should decrease the overall exit rate, because such constraints will only partially be compensated by more intensive search on the local market, a lower reservation wage, or acceptance of longer commutes. They thus explain the observed higher exit rates of homeowners on the local labor market, but contradict the higher overall exit rate that is also present in the data, as pointed out by Van Vuuren (2007). The higher overall exit rate of homeowners can be explained by extending the model in such a way that homeowners differ from tenants in other ways than just by the costs of residential mobility. Following this line of thought, Van Vuuren (2007) developed a non-stationary search model to reconcile theory with the empirical facts. In his model, long unemployment durations imply the risk of being forced to sell the house.

This does not, of course, exclude the possibility that there are other potentially important links between the housing and the labor markets. For example, an alternative possibility to reconcile the theory with the empirical facts was suggested by Rouwendal and Nijkamp (2010), who developed a model in which search intensity depends on the net income after housing costs. This model is consistent with higher exit rates from unemployment among homeowners, if their out-of-pocket housing costs are higher than that of otherwise comparable tenants. The authors show this to be the case for the Netherlands, but do not provide an analysis of unemployment durations. Earlier, Flatau et al. (2003) presented empirical work for Australia that suggested that mortgage payments could provide important incentives for job search. In particular, they showed that highly leveraged male workers were more likely to find a job soon after becoming unemployed than outright owners. In the next section we formulate an alternative version of the model of Rouwendal and Nijkamp (2010) that links the impact of housing costs on unemployment duration to risk attitude. 


\section{A search model for labor market and tenure choice interactions}

\subsection{Housing costs, risk aversion and job search}

We assume that job seekers have a utility function with housing characteristics $h$ (a vector) and other consumption $c$ (aggregated to a scalar composite with unit price equal to 1) as its arguments. The budget constraint is $y=c+p(h)$ where $y$ denotes (current) net income, and $p$ net out-of-pocket housing costs, which are a function of $h$. In the next subsection we introduce the spatial dimension of the labor market. Tenure is included as a characteristic in $h$, and we allow workers to attach a value to owning over renting. Rents are allowed to be different from the out-of-pocket housing costs of similar owner-occupied housing. Mortgage characteristics are also included in $h$, as they are an important determinant of out-of-pocket housing costs. Throughout the paper we assume housing characteristics, including housing cost, of unemployed job seekers to be predetermined and fixed, therefore assuming that there is no moving during unemployment. ${ }^{1}$ It is important to note that the model does not assume a simple dichotomy between tenants (with low housing costs) and owners (with high housing costs). Instead, we allow high as well as low housing costs for both tenure types. Outright owners have very low out-of-pocket housing costs, whereas highly leveraged owners living in a similar house can have very high housing costs, and this difference may have an important impact on their search behavior when unemployed.

We assume the indirect utility function $v$ to be additively separable in a part that refers to the consumption budget that remains after housing costs have been subtracted from income and a part that refers to housing:

$$
v=u_{1}(y-p(h))+u_{2}(h) .
$$

This formulation implies that the marginal utility of the composite consumption good is independent of $h$. Although one can often easily criticize separability assumptions, the formulation in (1) has the clear advantage that it emphasizes that living in a nice house does not affect one's need for food, clothing and other non-durables. An important implication of (1) is that housing characteristics (the vector $h$, not housing costs $p$ ) have no impact on labor market search behavior and thus do not appear in the Bellman equation below. The function $u_{1}$ is assumed to be increasing, concave, and twice differentiable.

To study unemployment durations, we adopt the familiar job search framework in which job seekers receive job offers that are random draws. ${ }^{2}$ The Bellman equation for optimal stationary job search is:

$$
\rho U=u_{1}(b-p(h))+\lambda \int_{0}^{\infty} \max \left\{\frac{u_{1}(y-p(h))}{\rho}-U, 0\right\} f(y) d y .
$$

\footnotetext{
1 The very low number of residential moves that we and others observe during unemployment spells confirm that this is a reasonable assumption.

2 See, for instance, Rogerson et al. (2005) for a review, and Rouwendal (1999) or Van Ommeren et al. (2000) for applications in a spatial setting.
} 
In this equation, $U$ is the value of unemployment; $b$ is the unemployment benefit; $\lambda$ is the arrival rate of job offers; $\rho$ is the discount rate; and $f(y)$ is the density of the wages of offered jobs. The optimal search strategy is to accept the first offer with a wage that gives a higher discounted utility than the value of unemployment $U$. This critical value, known as the reservation wage, is denoted as $y^{\text {res }}$. Plugging in $U=u_{1}\left(y^{r e s}-p(h)\right) / \rho$ in the above equation and solving for $u_{1}\left(y^{r e s}-p(h)\right)$ gives:

$$
u_{1}\left(y^{r e s}-p(h)\right)=\frac{\rho u_{1}(b-p(h))+\lambda \int_{y^{r e s}}^{\infty} u_{1}(y-p(h)) f(y) d y}{\rho+\lambda \int_{y^{r e s}}^{\infty} f(y) d y} .
$$

The exit rate from unemployment is equal to $\lambda \int_{y^{r e s}}^{\infty} f(y) d y$. The exit rate is decreasing with the reservation wage, so it is increasing in housing costs if $\partial y^{r e s} / \partial p(h)<0$. It is shown in the Appendix that this is the case if the utility function $u_{1}$ has a property known as decreasing absolute risk aversion (DARA), which means that wealthier people are willing to pay less to escape an additional risk. ${ }^{3}$ This is widely regarded as a plausible characteristic of human behavior. ${ }^{4}$

\subsection{Implications}

The analysis just presented extends that in Rouwendal and Nijkamp (2010), who consider a model with variable search intensity, but no variation in offered wage rates, and assume that the utility function is quadratic.

The main result derived above is that if DARA holds, workers with high housing costs have a higher exit rate from unemployment than otherwise comparable workers with lower housing costs. This is a potentially important prediction of the model that can be tested empirically. It provides a theoretical underpinning of the empirical results reported by Flatau et al. (2003) who showed for Australian data that highly leveraged male workers were more likely to find a job soon after becoming unemployed than outright owners. There is also a connection with the empirical work on the Oswald thesis, as the model developed above predicts that renters have longer unemployment durations than homeowners with higher housing costs, e.g. because they are highly leveraged, and shorter unemployment durations than homeowners with lower housing costs, e.g. because they have paid back the whole mortgage loan. This suggests that the validity of Oswald's thesis may depend on the mortgage market.

Note that we take the out-of-pocket expenses for housing here as an indicator of housing costs, and not the user costs. A priori, one expects user costs to be approximately equal to user costs when households can choose either type of tenure. If this is the case, out-of-pocket expenses for leveraged homeowners should be expected to be higher than those of renters, because they have to repay the mortgage. Moreover, we

\footnotetext{
3 Formally the property requires that $-u_{1}^{\prime \prime} / u_{1}^{\prime}$ is decreasing.

4 For instance, much empirical work in microeconomics assumes a utility function with constant relative risk aversion, which implies decreasing absolute risk aversion. Direct empirical evidence in favor of this property can be found, for instance, in Chiappori and Paiella (2011).
} 
note that almost all rental housing in the Netherlands is rent-controlled and that there are long waiting lists_-especially in larger cities_-for these houses. The consequence is that arbitrage between the rental and owner-occupied markets is limited, while the waiting lists strongly suggest that rental housing is cheaper. ${ }^{5}$ We test the relationship between mortgage size and unemployment exit rates in the Netherlands in Sect. 4.

\section{Empirical analysis}

\subsection{Empirical strategy}

Our theoretical framework predicts that higher out-of-pocket housing costs lead to higher exit rates from unemployment at the individual level. Thus, unemployed homeowners who are bound to a high mortgage find a job faster than comparable homeowners with lower mortgages. In addition, if the mortgage effect is behind the discrepancy found between Oswald's predictions and the results of previous analyses of microdata, then the inclusion of mortgage debt in our analysis is expected to significantly diminish the positive effect of homeownership on the chance of finding a job.

We test these predictions using a duration analysis model (see Lancaster 1990, for a detailed survey of this framework). In such a model, the dependent variable of interest is the hazard rate into employment, denoted by $\theta(t)$. It is defined as the probability of an individual leaving the state of unemployment into employment at the time interval $(t, t+d t)$, given that the individual is unemployed at time $t$. We employ the Cox (1972) Proportional Hazard specification, in which the hazard of an individual with observed characteristics $x$ is defined by

$$
\theta(t \mid x)=\lambda(t) \cdot \exp \left(x^{\prime} \beta\right)
$$

where $\lambda(t)$ is called the baseline hazard. No assumptions regarding the shape of $\lambda(t)$ are necessary for the estimation of the $\beta$ parameters using partial likelihood maximization.

Unobserved heterogeneity, not accounted for in our model, casts serious doubts on the consistency of the estimated effects of housing tenure and mortgage size. Obviously, the individual's position in the labor market can affect both her chance of finding a job and the level of mortgage she would take. A skilled individual, or one with a good employment history, would be more secure in her ability to return a higher loan, and the bank would be more willing to provide a high loan, than to an individual with a weaker labor market position. This type of heterogeneity would result in an overestimate of the effect of mortgage size on the exit from unemployment.

However, our reported results do not account for such heterogeneity. As Sect. 4.3 shows, we do not find any effect of mortgage size on the chance to leave unemployment. Moreover, the inclusion of mortgage does not significantly diminish the effect of homeownership (which also likely suffers from endogeneity issues, see Van Leu-

\footnotetext{
5 Rouwendal and Nijkamp (2010) find that Dutch renters have lower out-of-pocket expenses for housing than homeowners.
} 
vensteijn and Koning 2004). Even if the mortgage effect is overestimated, this result stands in contrast to our theoretical predictions.

\subsection{Data}

To test the predictions of our model, we have estimated a duration model for Dutch unemployment spells. Statistics Netherlands gave us access to the Sociaal Statistisch Bestand (SSB), which contains all unemployment benefits and all jobs in the Netherlands in the period 2001-2005. We defined an unemployment spell as a period where a person was not employed at any firm and received unemployment benefits. Our definition ensures full-time unemployment and eligibility of unemployment benefits. The latter requires that the receivers are available for the labor market and are actively searching for a job. The unemployment spell ends when one or both of these conditions no longer apply. If an unemployment spells ends, but we do not observe the start of a new job within one month, the spell is censored. This happens for example when the maximum duration of unemployment benefits is reached without finding a new job.

We merged the unemployment spells with data on individual workers and households. Statistics Netherlands provided us with the Gemeentelijke basisadministratie $(G B A)$ and the Inkomenspanelonderzoek (IPO), both for the period 2001-2005. The GBA is the Dutch municipality registry and contains the residential location and other demographic characteristics of all Dutch inhabitants. The GBA data allowed us to determine the age, gender and country of birth of the worker. We were also able to determine whether the worker had a partner or children. The IPO is a survey on incomes which covers about $0.7 \%$ of the Dutch population. It contains several measures of income for the individual worker and the household. It also includes net income, capital income and received rental subsidies. Additionally, it contains data on housing tenure and on the size of the mortgage and the value of the house.

In our empirical analysis we only include the first unemployment spell of each worker since 1999 to avoid repeated spells. We also removed unemployment spells that were shorter than two weeks and censored unemployment spells that were longer than two years. ${ }^{6}$ In addition, we removed observations with an income equal or lower than zero and owners with a house value equal or lower than zero. Observations of homeowners were also removed if their loan-to-value ratio is higher than 1.62 , which corresponds to the 99th percentile of this variable. The remaining number of unemployment spells is 10,341, of which 5,676 are owners and 4,665 are renters.

Figure 1 presents the distribution of the duration of unemployment spells, distinguishing between homeowners and renters. The durations are displayed in weeks (rounded down). Durations longer than 52 weeks are not shown in the histogram due to confidentiality reasons related to the low number of spells ending in certain weeks. After these 52 weeks, $79 \%$ of the spells of owners and $81 \%$ of the spells of renters have ended, either because the person found a new job or because the spell was censored. The peak at 26 weeks can be explained by the fact that this was the minimum

\footnotetext{
6 We also repeated the estimations while including all unemployment spells. The results were very similar and are available on request.
} 


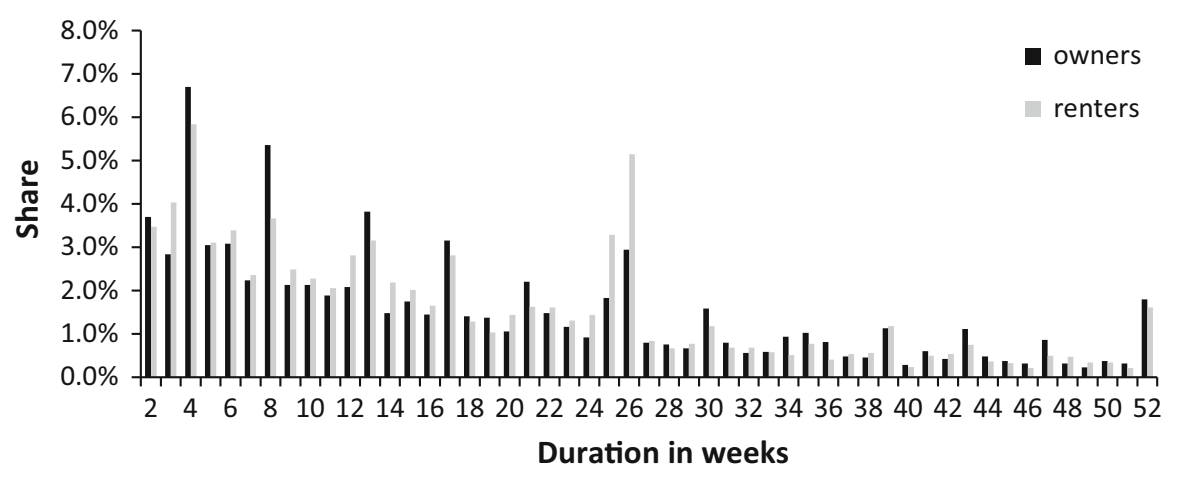

Fig. 1 Histogram of duration of unemployment spells
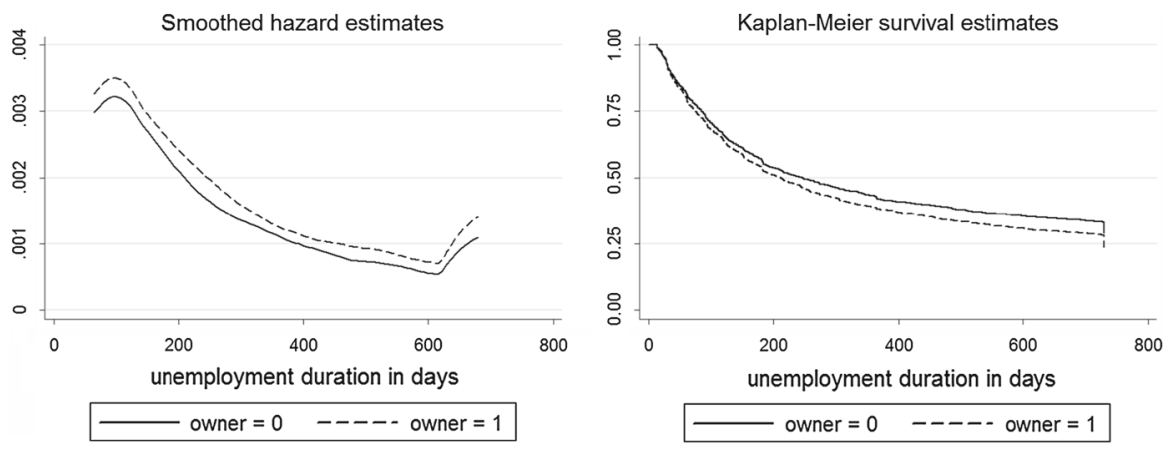

Fig. 2 Smoothed Kaplan-Meier hazard rates and survival rates

period of eligibility for unemployment benefits, which causes relatively many spells to be censored at that moment.

Figure 2 contains the smoothed Kaplan-Meier hazard rates and the survival rates for homeowners and renters. The hazard rate is generally decreasing over time. This figure also shows that the exit rate is higher for homeowners than for renters at any duration. In Sect. 4.3 we provide more formal estimation results where we also control for other workers' characteristics.

Table 1 shows descriptive statistics of the unemployment duration spells and the explanatory variables, for owners, renters and all observations. The average duration of the unemployment spells is higher for owners than for renters, but this may also be related to censoring. The share of uncensored spells is higher for owners (59\%) than for renters (52\%). As expected, homeowners have higher average household incomes and have more often financial assets.

\subsection{Estimation results}

We estimate six specifications of the Proportional Hazard model. In specification I, the hazard is a function of housing tenure, and of whether the individual receives 
Table 1 Descriptive statistics

\begin{tabular}{llll}
\hline & All $(10,341)$ & Owners $(5,676)$ & Renters $(4,665)$ \\
\hline Unemployment duration in days & $224.1(219.8)$ & $227.9(221.2)$ & $219.5(217.9)$ \\
Finds a job & 0.556 & 0.591 & 0.515 \\
Female & 0.471 & 0.481 & 0.458 \\
Foreign & 0.235 & 0.138 & 0.353 \\
Couple & 0.838 & 0.935 & 0.720 \\
At least one child in household & 0.545 & 0.588 & 0.493 \\
Age & $39.32(10.08)$ & $40.69(9.67)$ & $37.64(10.32)$ \\
Financial assets below threshold & 0.875 & 0.807 & 0.958 \\
Receives rental subsidies & 0.116 & 0 & 0.257 \\
Owner & 0.549 & 1 & 0 \\
Net household income $(\times 1,000$ euro $)$ & $30.94(16.48)$ & $35.88(18.14)$ & $24.94(11.67)$ \\
Mortgage size $(\times 1,000$ euro $)$ & $76.34(103.05)$ & $139.09(103.05)$ & $0(0)$ \\
Loan-to-value ratio & $0.340(0.405)$ & $0.619(0.354)$ & $0(0)$ \\
\hline
\end{tabular}

Standard errors are shown in parentheses (not shown for dummy variables)

rental subsidies, as well as of an array of control variables. Specification II adds the mortgage size and the net household income. Specification III replaces these two variables for the ratio of mortgage to house value. These three specifications are then repeated using a subsample that includes unemployment spells of homeowners only. In all specifications we control for the province of residence and the year at the start of the unemployment spell (coefficients not reported).

The estimates of the $\beta$ coefficients of our empirical model are reported in Table 2. The proportional effect of each independent variable on the hazard is computed by taking the exponent of the reported coefficient. The effects of the control variables are very similar across specifications, and their signs and magnitudes are as expected. In model specification I, the exit rate out of unemployment of females is about $20 \%$ lower than that of males. Those that are born in a foreign country are $29 \%$ less likely to find a job than those born in the Netherlands. The exit rate is generally not affected by having another adult in the household, but the presence of children reduces it by about $18 \%$. The chance of finding a new job decreases with age. Compared with workers younger than 30, those in age groups 30-40, 40-50, and 50 and up, have an exit rate which is lower by 26,34 , and $78 \%$, respectively. We do not find a clear significant effect of the extent of the household's financial assets.

Renters who receive rental subsidies have an exit rate that is about $12 \%$ smaller than that of renters who do not receive them. It is possible that this is related to higher transaction costs of moving from subsidized social housing, which is usually allocated by waiting lists. This effect may be overestimated, since a low income is a condition for receiving rental subsidies, while also indicating a weaker labor market position.

The results show that the exit rate of owners is 11-20\% higher compared to renters. This finding is clearly inconsistent with Oswald's thesis. However, it is in line with previous microeconometric studies (Munch et al. 2006, for Denmark; Battu et al. 2008, for the UK; Van Vuuren 2007, for the Netherlands). As pointed out by Munch et al. 


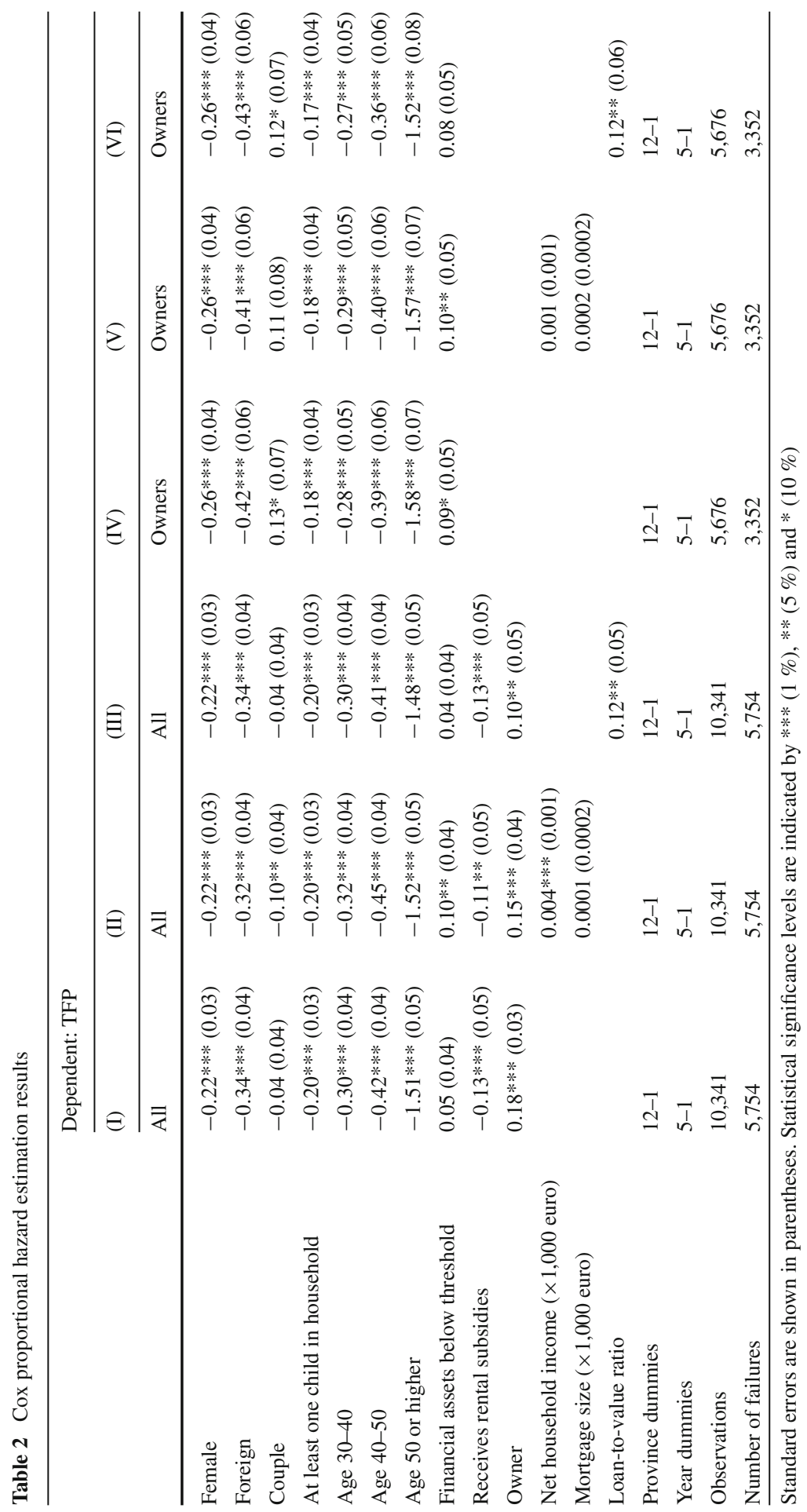


(2006) and others, this effect may be prone to selection bias, as households with a preference for stability may be more likely to own a house, as well as less likely to adapt and move in response to a local labor market shock.

In specification II, we add the net income of the household and the size of the mortgage. For every additional 1,000 euro of net income, the hazard rate increases by $0.4 \%$. The disappearance of this effect in the subsample of homeowners in specification $\mathrm{V}$ suggests that here too, correlations with unobservables play a role.

The effect of mortgage size is statistically and economically insignificant. As described in Sect. 4.1, the potential upward bias of this effect does not seem to spoil our analysis. It does, however, stand in contrast to our theoretical predictions, all the more so as the homeownership effect does not differ significantly from that in specification I.

In specification III, we find a statistically significant coefficient for the loan-to-value ratio. Homeowners with a mortgage that is equal to the value of the house are about $13 \%$ more likely to leave unemployment compared to outright owners. Although there is a potential upward bias here if workers with a stronger labor market position are more likely to take up higher leverage, this result suggests that a theory based on financial leverage would be more appropriate than our current model. Including the loan-to-value ratio also diminishes the effect for homeownership, suggesting that part of the homeownership effect is explained by the fact that many homeowners have borrowed a high share of their house.

\section{Conclusion}

In this paper we discussed some issues raised by the empirical literature that investigates the validity of Oswald's thesis by analyzing unemployment duration. We proposed a search model that emphasizes the relationship between housing costs, that are interpreted as fixed in the short-run, and the exit rate of unemployment. If the worker's utility has the property of decreasing absolute risk aversion (DARA), higher housing costs imply a higher hazard rate of leaving unemployment.

We tested this prediction on unemployment durations in the Netherlands in the period 2001-2005. We could not find robust evidence that supports our hypothesis. In line with earlier empirical research we also find that homeowners are more likely to leave unemployment than renters, which does not support Oswald's thesis. Blanchflower and Oswald (2013) suggest that a different approach, that focuses on labor market externalities generated with long time lags by homeownership might be more fruitful.

Our results suggest that rather than focusing on out-of-pocket housing costs, a theory that relates job search behavior and financial leverage should be developed and tested. In an empirical application, financial leverage may suffer from selection bias. Therefore, the choice of individual leverage may be controlled for in the spirit of homeownership selection employed by Munch et al. (2006) and Van Leuvensteijn and Koning (2004), among others.

Acknowledgments This is an adapted version of Kantor, Y., P. Nijkamp and J. Rouwendal (2013), Homeownership, Unemployment and Commuting Distances, TI Discussion Paper 2013-144/VIII. 
Open Access This article is distributed under the terms of the Creative Commons Attribution License which permits any use, distribution, and reproduction in any medium, provided the original author(s) and the source are credited.

\section{Appendix: The effect of housing costs on the reservation wage}

We repeat (3) here as:

$$
u_{1}\left(y^{r e s}-p(h)\right)=\frac{\rho u_{1}(b-p(h))+\lambda \int_{y>y^{r e s}} u_{1}(y-p(h)) f(y) d y}{\rho+\lambda \int_{y>y^{r e s}} f(y) d y},
$$

and consider the impact of an increase of the housing costs on the reservation wage. We can use this equation to investigate the change in the reservation wage that results from a small change in the housing cost, computing $d y^{r e s} / d p(h)$. The condition for this ratio to be negative can be written as:

$$
u_{1}^{\prime}\left(y^{r e s}-p(h)\right)>\frac{\rho u_{1}^{\prime}(b-p(h))+\lambda \int_{y>y^{r e s}} u_{1}^{\prime}(y-p(h)) f(y) d y}{\rho+\lambda \int_{y>y^{r e s}} f(y) d y},
$$

where the primes denote first derivatives with respect to $p(h)$.

An alternative interpretation of (4) is that it represents the certain income $z^{c e r}=$ $y^{r e s}-p(h)$ that is equivalent (in terms of expected utility) to the uncertain income $z$ which is equal to a certain base value $z^{b}=b-p(h)$ plus an uncertain component $\varepsilon$. The uncertain component has a probability distribution that is partly discrete and partly continuous. It equals 0 with a positive probability (mass point):

$$
\rho /\left(\rho+\lambda \int_{z>0} f^{*}(\varepsilon) d \varepsilon\right)
$$

and $\varepsilon>0$ with probability density:

$$
\lambda f^{*}(\varepsilon) /\left(\rho+\lambda \int_{\varepsilon>0} f^{*}(\varepsilon) d \varepsilon\right)
$$

where $f^{*}(\varepsilon)=f(\varepsilon+b+p(h))$ if $\varepsilon+b>y^{r e s}$ and $f^{*}(\varepsilon)=0$ otherwise. We can now rewrite (4) as:

$$
u_{1}\left(z^{c e r}\right)=\frac{\rho u_{1}\left(z^{b}\right)+\lambda \int_{\varepsilon>0} u_{1}\left(z^{b}+\varepsilon\right) f^{*}(\varepsilon) d \varepsilon}{\rho+\lambda \int_{\varepsilon>0} f^{*}(\varepsilon) d y}
$$

Now consider what happens with the equivalent certain income $z^{c e r}$, if all incomes on the right-hand-side of the equation change by the same small positive amount $d z^{*}$. That is, $z^{b}$ changes with $d z$. If utility has the property of decreasing absolute risk aversion (DARA), the consumer needs less compensation for taking a particular amount of risk when his or her wealth is higher (see, for instance, Gollier 2001, p. 24). Utility thus has DARA, if the increase in the certain income $d z^{c e r}$ needed to maintain the equality 
sign in (5) is less than $d z$. It is not difficult to verify that $d z^{c e r} / d z$ is less than 1 if:

$$
u_{1}^{\prime}\left(z^{c e r}\right)>\frac{\rho u_{1}^{\prime}\left(z^{b}\right)+\lambda \int_{\varepsilon>0} u_{1}^{\prime}\left(z^{b}+\varepsilon\right) f^{*}(\varepsilon) d \varepsilon}{\rho+\lambda \int_{\varepsilon>0} f^{*}(\varepsilon) d y} .
$$

Except for the notation, this equation is identical to (5). We have therefore shown that in our model an increase in housing costs decreases the reservation wage iff the worker's utility function has DARA.

\section{References}

Battu, H., Ma, A., Phimister, E.: Housing tenure, job mobility and unemployment in the UK. Econ. J. 118, 311-328 (2008)

Blanchflower, D.G., Oswald, A.J.: Does high home-ownership impair the labor market? NBER Working Paper 19079 (2013)

Chetty, R., Szeidl, A.: Consumption commitments and risk preferences. Q. J. Econ. 122, 831-877 (2007)

Chiappori, P.A., Paiella, M.: Relative risk aversion is constant: evidence from panel data. J. Eur. Econ. Assoc. 9, 1021-1052 (2011)

Coulson, N.E., Fisher, L.M.: Housing tenure and labour market impacts. J. Urban Econ. 65, 252-264 (2009)

Cox, D.R.: Regression and life tables (with discussion). J. R. Stat. Soc. B 34, 187-220 (1972)

Flatau, P., Forbes, M., Hendershott, P.H., Wood, G.: Homeownership and unemployment: the roles of leverage and public housing. NBER Working Paper 10021 (2003)

Gollier, C.: The Economics of Risk and Time. MIT Press, Cambridge (2001)

Green, R., Hendershott, P.: Homeownership and unemployment in the US. Urban Stud. 38, 1501-1520 (2001)

Lancaster, T.: The Analysis of Transition Data. Cambridge University Press, New York (1990)

Munch, J.R., Rosholm, M., Svarer, M.: Are home owners really more unemployed? Eco. J. 116, 991-1013 (2006)

Oswald, A.J.: A conjecture on the explanation for high unemployment in the industrialized nations: part I. Working Paper 475, Department of Economics, University of Warwick, Coventry (1996)

Oswald, A.: Thoughts on Nairu. J. Econ. Perspect. 11, 227-228 (1997)

Oswald, A.J.: The housing market and Europe's unemployment: a non-technical paper. In: van Ewijk, C., van Leuvenstijn, M. (eds.) Homeownership and the Labour Market in Europe. Oxford University Press, Oxford (1999)

Rogerson, R., Shimer, R., Wright, R.: Search-theoretic models of the labor market: a survey. J. Econ. Lit. 43, 959-988 (2005)

Rouwendal, J., Nijkamp, P.: Homeownership and labour-market behaviour: interpreting the evidence. Environ. Plan. A 42, 419-433 (2010)

Van den Berg, G.J., Gorter, C.: Job search and commuting time. J. Bus. Econ. Stat. 15, 269-281 (1997)

Van Leuvensteijn, M., Koning, P.: The effect of home-ownership on labour mobility in the Netherlands. J. Urban Econ. 55, 580-596 (2004)

Van Ommeren, J., Rietveld, P., Nijkamp, P.: Job mobility, residential mobility and commuting. Ann. Reg. Sci. 34, 213-232 (2000)

Van Vuuren, A.: The relationship between expectations of labour market status, homeownership and the duration of unemployment. EEA Working Paper (2007). http://www.eea-esem.com/files/papers/ EEA-ESEM/2007/1916/housing.pdf. Accessed 31 Jan 2015 (2007) 